Research Journal of Applied Sciences 14 (6): 198-207, 2019

ISSN: $1815-932 \mathrm{X}$

(C) Medwell Journals, 2019

\title{
Numerical Study of Viscous Dissipation and Chemical Reaction in MHD Nanofluid
}

\author{
${ }^{1} \mathrm{~K}$. Govardhan, ${ }^{2} \mathrm{G}$. Narender and ${ }^{2} \mathrm{G}$. Sreedhar Sarma \\ ${ }^{1}$ Department of Mathematics, Gandhi Institute of Technology and Management, \\ University Hyderabad, Telangana State, India \\ ${ }^{2}$ Department of Mathematics, CVR College of Engineering, \\ Hyderabad, Telangana State, India
}

\begin{abstract}
A study of viscous dissipation and chemical reaction effects of nanofluid flow passing over a stretched surface with the MHD stagnation point and the convective boundary condition has been analyzed numerically. The constitutive equations of the flow model are solved numerically and the impact of physical parameters concerning the flow model on dimensionless velocity, temperature and concentration are presented through graphs and tables. Also, a comparison of the obtained numerical results with the published results of W. Ibrahim has been made and found that both are in excellent agreement.
\end{abstract}

Key words: Magnetohydrodynamic, stretching sheet, nanofluid, viscous dissipation, chemical reaction, concerning

\section{INTRODUCTION}

During the past few years, investigating the stagnation point flow of nanofluids has become more popular among the researchers. Nanofluids are formed by the suspension of the nanoparticles in conventional base fluids. Examples of such fluids are water, oil or other liquids. The nanoparticles conventionally made up of carbon nanotubes, carbides, oxides or metals are used in the nanofluids. Keen interest has been taken by many researchers in the nanofluids as compared to the other fluids because of their significant role in industry, medical field and a number of other useful areas of science and technology. Some prominent applications of these fluids are found in magnetic cell separation, paper production, glass blowing, cooling the electronic devices by the cooling pad during the excessive use, etc. Choi (1995) introduced the idea of nanofluids for improving the heat transfer potential of the conventional fluids. He experimentally concluded with an evidence that injection of these particles helps in improving the fluid's thermal conductivity. This conclusion opened the best approach to utilize such fluids in mechanical engineering, chemical engineering, pharmaceuticals and numerous different fields. Buongiorno (2006), Kuznetsov and Nield (2010) followed him and extended the investigation. They worked on the effects of Brownion motion in convective transport of nanofluids and the investigation of natural convective transport of nanofluids passing over a vertical surface in a situation when nanoparticles are dynamically controlled at the boundary. Khan and Pop (2011) used this concept to evaluate the laminar boundary layer flow, nanoparticles fraction and heat transfer for nanofluids passing over a stretching surface.

In industrial sector and modern technology, the non-Newtonian fluids play a vital role. Non-Newtonian fluids have some interesting applications as they are used in the manufacturing of sports shoes, flexible military suits and viscous coupling. Rising inception of the non-Newtonian fluids like emulsions, molten plastic pulp, petrol and many other chemicals has triggered an appreciable interest in the study of the behavior of such fluids during motion. The mathematical solutions of the models involving the non-Newtonian fluids are quite interesting and physically applicable. Makinde et al. (2013) investigated the buoyancy effect on magnetohydrodynamic stagnation point flow and heat transfer of nanofluids passing over a convectively heated stretching/shrinking sheet. The MHD fluid passing over a stretched sheet, through the porous media with the thermal radiation and the thermal conductivity was examined by Cortell (2012).

Naramgari and Sulochana (2016) outlined the mass and heat transfer of the thermophoretic fluid flow past an exponentially stretched surface inserted in porous media in the presence of internal heat generation/absorption, infusion and viscous dissemination. Afify (2004) examined the MHD free convective heat and fluid flow passing over the stretched surface with chemical reaction. A numerical analysis of insecure $\mathrm{MHD}$ boundary layer flow of a nanofluid past an stretched surface in a porous media was carried out by

Corresponding Author: G. Narender, Department of Mathematics, CVR College of Engineering, Hyderabad, Telangana State, India 
Beg et al. (2014). Nadeem and Haq (2014) studied the magnetohydrodynamic boundary layer flow with the effect of thermal radiation over a stretching surface with the convective boundary conditions.

Our prime objective is we first reproduce an analysis study by Ibrahim and Haq (2016) and then extend the MHD stagnation point flow of nanofluid past a stretching sheet with convective boundary condition. "According to our information, viscous dissipation and chemical reaction effects on MHD mixed convection stagnation point flow of nanofluid over a stretching surface" is not yet examined. An appropriate similarity transformation has been utilized to acquire the system of nonlinear and coupled ODEs from the system of PDEs. Results are acquired numerically by using the comprehensive shooting scheme. The numerical results are analyzed by graphs for different parameters which appear in the solution affecting the MHD mixed convection stagnation point.

\section{MATERIALS AND METHODS}

Mathematical formulation: Consider the stagnation point flow of two-dimensional viscous steady flow of nanofluid passing over a stretched surface with the convective $\mathrm{BC}$. The stretching sheet was heated with the temperature $T_{f}$ and the heat transfer coefficient $h_{f}$ at its lower surface. Here, concentration and uniform ambient temperature are respectively, $\mathrm{C}_{\infty}$ and $\mathrm{T}_{\infty}$.

Assume that at the surface there is not any nanoparticle flux and the impacts of the thermophoresis is taken as a BC. In flow model, $\mathrm{u}_{\mathrm{w}}(\mathrm{x})=\mathrm{ax}$ is the velocity of the stretching surface where, "a" is any constant.
In the direction of the flow, normal to the surface, it is directed towards the magnetic field of strength $B_{0}$ which is supposed to be applied in the direction of +ve y-axis. Here, magnetic field is negligible because of assumption of very small when comparing with the applied magnetic field. The preferred system of coordinates is such as $\mathrm{x}-$ axis is directed to the flow and $y$-axis is perpendicular to it. Proposed coordinate system and flow model are presented in Fig. 1.

Flow model of Ibrahim and Haq (2016) shows that in the presence of magnetic field over the surface, the governing equations of conservation of momentum, energy, mass and nanoparticle fraction under the boundary layer approximation are as follows:

$$
\begin{gathered}
\frac{\partial \mathrm{u}}{\partial \mathrm{x}}+\frac{\partial \mathrm{v}}{\partial \mathrm{y}}=0 \\
\mathrm{u} \frac{\partial \mathrm{u}}{\partial \mathrm{x}}+\mathrm{v} \frac{\partial \mathrm{v}}{\partial \mathrm{y}}=v \nabla^{2} \mathrm{u}+\mathrm{U}_{\infty} \frac{\partial \mathrm{U}_{\infty}}{\partial \mathrm{x}}+\frac{\sigma \mathrm{B}_{0}^{2}}{\rho \mathrm{f}}\left(\mathrm{U}_{\infty}-\mathrm{u}\right) \\
\mathrm{u} \frac{\partial \mathrm{T}}{\partial \mathrm{x}}+\mathrm{v} \frac{\partial \mathrm{T}}{\partial \mathrm{y}}=\alpha \nabla^{2} \mathrm{~T}-\frac{1}{\rho \mathrm{c}_{\mathrm{p}}} \frac{\partial \mathrm{q}_{\mathrm{r}}}{\partial \mathrm{y}}+\frac{\nu}{\rho \mathrm{c}_{\mathrm{f}}}\left(\frac{\partial \mathrm{u}}{\partial \mathrm{y}}\right)^{2}+ \\
\tau\left(\mathrm{D}_{\mathrm{B}} \nabla \varphi \cdot \nabla \mathrm{T}+\frac{\mathrm{D}_{\mathrm{T}}}{\mathrm{T}_{\infty}} \nabla \mathrm{T} \cdot \nabla \mathrm{T}\right) \\
\mathrm{u} \frac{\partial \varphi}{\partial \mathrm{x}}+\mathrm{v} \frac{\partial \varphi}{\partial \mathrm{y}}=\alpha \nabla^{2} \mathrm{~T}+\mathrm{D}_{\mathrm{B}} \nabla^{2} \varphi+\frac{\mathrm{D}_{\mathrm{T}}}{\mathrm{T}_{\infty}} \nabla^{2} \mathrm{~T}-\mathrm{k}_{0}\left(\mathrm{C}-\mathrm{C}_{\infty}\right)
\end{gathered}
$$

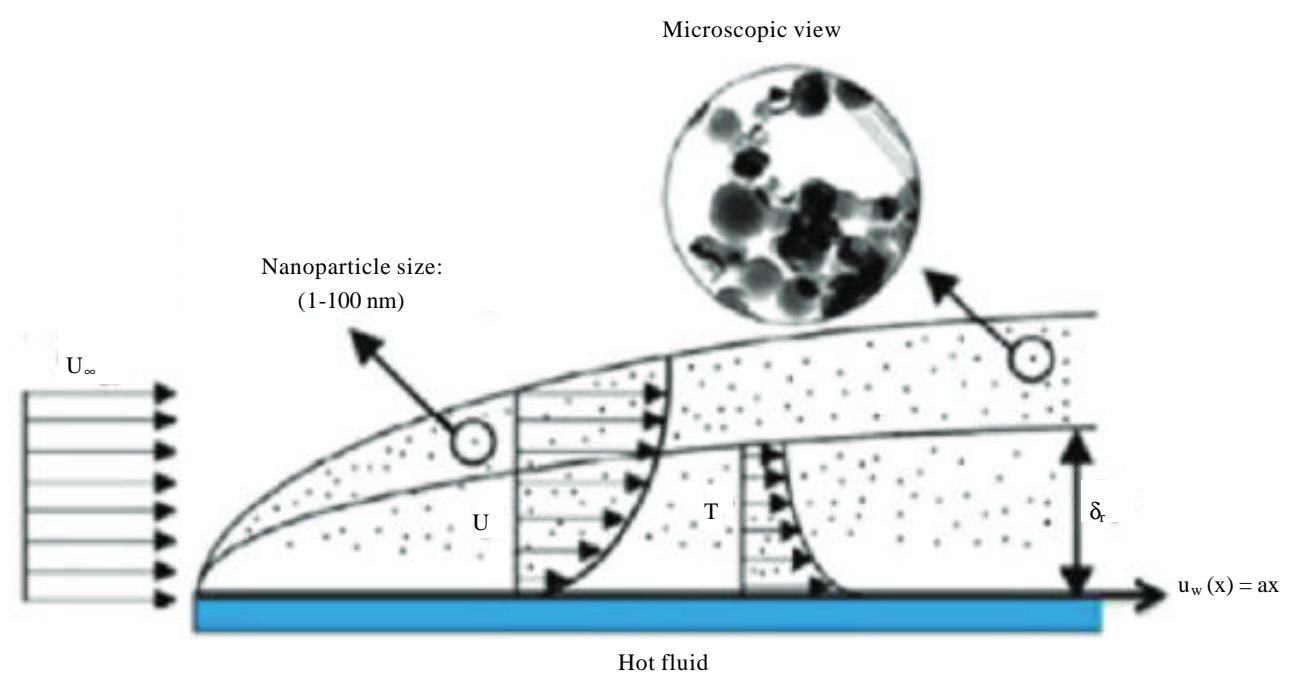

Fig. 1: Geometry for the flow under consideration 


$$
\left.\begin{array}{l}
u=u_{w}=a x, v=0,-k \frac{\partial T}{\partial y}=h_{f}\left(T_{f}-T\right), \\
D_{B} \frac{\partial \varphi}{\partial y}+\frac{D_{T}}{T_{\infty}} \frac{\partial_{T}}{\partial y}=0 \text { at } y=0 \\
u \rightarrow U_{\infty}=b x, v=0, T \rightarrow T_{\infty}, \varphi \rightarrow \varphi_{\infty}, \text { as } y=\infty
\end{array}\right\}
$$

where, $\mathrm{x}$ is the coordinate axis along the continuous surface in the direction of motion and $y$ is the coordinate axis along the continuous surface in the direction perpendicular to the motion. The components of velocity along $\mathrm{x}$-axis and $\mathrm{y}$-axis are respectively, $\mathrm{u}$ and $\mathrm{v}$. Here, kinematic velocity is represented by $\mathrm{v}$ and $\mathrm{T}$ represents the temperature inside the boundary layer. The parameter $\tau$ is defined by $\tau=(\rho c)_{\mathrm{p}} /(\rho c)_{\mathrm{f}}$ where, $(\rho c)_{\mathrm{p}}$ is effective heat capacity of nanoparticles and $(\rho c)_{\mathrm{f}}$ is heat capacity of base fluid, $\rho$ is the density and $T_{\infty}$ is the ambient temperature far away from the surface. The radiative heat flux $q_{r}$ is given as:

$$
\mathrm{q}_{\mathrm{r}}=\frac{-4 \sigma^{*}}{3 \mathrm{k}^{*}} \frac{\partial \mathrm{T}^{4}}{\partial \mathrm{y}}
$$

where, $\sigma^{*}$ and $k^{*}$ stand for the Stefan-Boltzmann constant and coefficient of mean absorption and $\mathrm{T}^{4}$ is the linear sum of temperature and it can expand with the help of Taylor series along with $\mathrm{T}_{\infty}$ :

$$
\mathrm{T}^{4}=\mathrm{T}_{\infty}^{4}+4 \mathrm{~T}_{\infty}^{3}\left(\mathrm{~T}-\mathrm{T}_{\infty}\right)+6 \mathrm{~T}_{\infty}^{2}\left(\mathrm{~T}-\mathrm{T}_{\infty}\right)^{2}+
$$

Ignoring higher order terms we get:

$$
\mathrm{T}^{4}=4 \mathrm{~T}_{\infty}^{3} \mathrm{~T}-3 \mathrm{~T}_{\infty}^{4}
$$

Substituting Eq. 8 into Eq. 6 we get:

$$
\mathrm{q}_{\mathrm{r}}=\frac{-16 \mathrm{~T}_{\infty}^{3} \sigma^{*}}{3 \mathrm{k}^{*}} \frac{\partial \mathrm{T}}{\partial \mathrm{y}}
$$

Dimensionless form of the model: To convert the PDEs Eq. 1-4 along with the $\mathrm{BCs}(5)$ into the dimensionless form we use the similarity transformation Ibrahim and Haq (2016):

$$
\begin{aligned}
& \eta=y \sqrt{\frac{a}{v}}, \psi=\sqrt{\mathrm{avx}} \mathrm{f}(\eta), \theta(\eta)=\frac{T-T_{\infty}}{\mathrm{T}_{\mathrm{f}}-\mathrm{T}_{\infty}}, \\
& \beta(\eta)=\frac{\varphi-\varphi_{\infty}}{\varphi_{w}-\varphi_{\infty}}
\end{aligned}
$$

In above, $\psi(\mathrm{x}, \mathrm{y})$ denotes stream function obeying:

$$
\mathrm{u}=\frac{\partial \psi}{\partial \mathrm{y}}, \mathrm{v}=-\frac{\partial \psi}{\partial \mathrm{x}}
$$

The equation of continuity (1) is satisfied identically, the effect of stream function on the remaining three equations, the momentum Eq. 2, the temperature Eq. 3 and concentration Eq. 4 are as:

$$
\begin{gathered}
\mathrm{f}^{\prime \prime \prime}+\mathrm{ff}^{\prime \prime}-\left(\mathrm{f}^{\prime}\right)^{2}+\mathrm{M}\left(\mathrm{A}-\mathrm{f}^{\prime}\right)+\mathrm{A}^{2}=0 \\
\frac{\left(1+\frac{4}{3} \mathrm{Nr}\right) \theta^{\prime \prime}}{\operatorname{Pr}}+\mathrm{f} \theta^{\prime}+\mathrm{Nb} \theta \beta^{\prime}+\mathrm{Nt}(\theta)^{2}+\mathrm{Ec}\left(\mathrm{f}^{\prime \prime}\right)^{2}=0 \\
\beta^{\prime \prime}+\operatorname{Lef} \beta^{\prime}+\frac{\mathrm{Nt}}{\mathrm{Nb}} \theta^{\prime \prime}-\mathrm{Le}_{\mathrm{c}} \beta=0
\end{gathered}
$$

The BCs get the form:

$$
\begin{aligned}
& \mathrm{f}(0)=0, \mathrm{f}^{\prime}(0)=1, \theta^{\prime}(0)=-\mathrm{Bi}[1-\theta(0)], \\
& \mathrm{Nb} \beta^{\prime}(0)+\mathrm{Nt} \theta^{\prime}(0)=0, \text { at } \eta=0 \\
& \mathrm{f}^{\prime}(\infty) \rightarrow \mathrm{A}, \theta(\infty) \rightarrow 0, \beta(\infty) \rightarrow 0 \text { as } \eta \rightarrow \infty
\end{aligned}
$$

In Eq. $12-14$, the governing parameters are defined as $\mathrm{Nr}=-4 \mathrm{~T}_{\omega}^{3} \sigma^{*} / 3 \mathrm{k} * \mathrm{k}$ is the radiation parameter $\operatorname{Pr}=v / \alpha$ is Prandtl number, $\mathrm{Le}=\alpha / \mathrm{D}_{\mathrm{B}}$ is Lewis number, $\mathrm{M}$ $=\sigma \mathrm{B}_{0}^{2} / \rho_{\mathrm{f}} \mathrm{a}$ is a magnetic parameter, $\mathrm{A}=\mathrm{b} / \mathrm{a}$ is velocity ratio parameter, $\mathrm{Nb}=\rho_{\mathrm{p}} \mathrm{D}_{\mathrm{B}}\left(\mathrm{C}_{\mathrm{w}}-\mathrm{C}_{\infty}\right) / \rho_{\mathrm{f}} \alpha$ is Browian motation parameter, $\mathrm{Nt}=\rho_{\mathrm{p}} \mathrm{D}_{\mathrm{T}}\left(\mathrm{T}_{\mathrm{W}}-\mathrm{T}_{\infty}\right) / \rho_{\mathrm{f}} \alpha \mathrm{T}_{\infty}$ thermophoresis parameter, $\mathrm{Bi}=\mathrm{h}_{\mathrm{f}} \mathrm{k} \sqrt{v / \mathrm{a}}$ Biot mumber, $\mathrm{Ec}$ $=\mathrm{u}_{\mathrm{w}}^{2} / \rho_{\mathrm{f}}\left(\mathrm{T}_{\mathrm{w}}-\mathrm{T}_{\infty}\right)$ is the Eckert number and $\mathrm{k}_{\mathrm{c}}=\mathrm{K}_{0} \mathrm{U}\left(\mathrm{C}_{\mathrm{w}}{ }^{-}\right.$ $\left.\mathrm{C}_{\infty}\right) / v$ is the chemical reaction parameter.

In this problem, the desired physical quantities are the local Nusselt number $\mathrm{Nu}_{\mathrm{x}}$ and reduced Sherwood number $\mathrm{Sh}_{\mathrm{x}}$ and the skin-friction coefficient $\mathrm{C}_{\mathrm{f}}$. These quantities are defined as:

$$
\begin{aligned}
& \mathrm{C}_{\mathrm{f}}=\frac{\tau_{\mathrm{w}}}{\rho u_{\mathrm{w}}^{2}}, \mathrm{Nu}_{\mathrm{z}}=\frac{\mathrm{xq}_{\mathrm{w}}}{\mathrm{k}\left(\left(\mathrm{T}_{\mathrm{w}}-\mathrm{T}_{\infty}\right)\right.}, \\
& \mathrm{Sh}_{\mathrm{z}}=\frac{\mathrm{xh}_{\mathrm{m}}}{\mathrm{D}_{\mathrm{B}}\left(\left(\varphi_{\mathrm{w}}-\varphi_{\infty}\right)\right.}
\end{aligned}
$$

Where:

$\tau_{\mathrm{w}}$ : The shear stress along the stretching surface

$\mathrm{q}_{\mathrm{w}}$ : The heat flux from the stretching surface

$h_{w}$ : The wall mass flux are given as 


$$
\begin{aligned}
& \tau_{w}=\mu\left(\frac{\partial u}{\partial y}\right)_{y=0}, q_{w}=-k\left(\frac{\partial T}{\partial y}\right)_{y=0}, \\
& h_{m}=-D_{B}\left(\frac{\partial \varphi}{\partial y}\right) y=0
\end{aligned}
$$

With the help of above equations, we get:

$$
C_{f} \sqrt{R_{x}}=-f^{\prime \prime}(0), \frac{N u_{z}}{\sqrt{R_{z}}}=-\theta^{\prime}(0), \frac{S h_{z}}{\sqrt{R_{x}}}=-\beta^{\prime}(0)
$$

where, $R_{x}=a x^{2}$ is the local Reynolds number.

Numerical results: The analytic solution of system of equations with corresponding boundary conditions Eq. 12-14 cannot be found because they are nonlinear and coupled. So, we use numerical technique, i.e., shooting-Newton technique with fourth order Adam's-Moultan method. In order to solve the system of ordinary differential Eq. 12-14 with boundary conditions Eq. 15-16 using shooting method we have to convert these equations into a system of first order differential Eq. 20, let:

$$
\begin{aligned}
& \mathrm{f}=\mathrm{y}_{1}, \mathrm{f}^{\prime}=\mathrm{y}_{1}^{\prime}=\mathrm{y}_{2}, \mathrm{f}^{\prime \prime}=\mathrm{y}_{2}^{\prime}=\mathrm{y}_{3}, \\
& \theta=y_{4}, \theta^{\prime}=y_{4}^{\prime}=y_{5}, \theta^{\prime \prime}=y_{5}^{\prime} \text {, } \\
& \left.\beta=y_{6}, \beta^{\prime}=y_{6}^{\prime}=y_{7}, \beta^{\prime \prime}=y_{7}^{\prime}\right\}
\end{aligned}
$$

Then the coupled nonlinear momentum, temperature and concentration equations are converted into system of seven first order simultaneous equations and the corresponding boundary conditions transforms the following form:

$$
\begin{gathered}
\mathrm{y}_{1}^{\prime}=\mathrm{y}_{2}, \mathrm{y}_{1}(0)=0 \\
\mathrm{y}_{2}^{\prime}=\mathrm{y}_{3}, \mathrm{y}_{2}(0)=1 \\
\mathrm{y}_{3}^{\prime}=\mathrm{y}_{2}^{2}-\mathrm{M}\left(\mathrm{A}-\mathrm{y}_{2}\right)-\mathrm{y}_{1} \mathrm{y}_{3}-\mathrm{A}^{2}, \mathrm{y}_{3}(0)=\mathrm{r} \\
\mathrm{y}_{4}^{\prime}=\mathrm{y}_{5}, \mathrm{y}_{4}(0)=\mathrm{s} \\
\mathrm{y}_{5}^{\prime}=-\frac{\operatorname{Pr}}{1+\mathrm{R}}\left(\mathrm{y}_{1} \mathrm{y}_{5}+\mathrm{Nby}_{5} \mathrm{y}_{7}+\mathrm{Nty}_{5}^{2}+\mathrm{Ecy}_{3}^{2}\right), \\
\mathrm{y}_{5}(0)=\mathrm{Bi}(\mathrm{s}-1) \\
\mathrm{y}_{6}^{\prime}=\mathrm{y}_{7}, \mathrm{y}_{6}(0)=\mathrm{t} \\
\mathrm{y}_{7}^{\prime}=-\mathrm{Ley}_{1} \mathrm{y}_{7}-\frac{\mathrm{Nt}}{\mathrm{Nb}} \mathrm{y}_{5}^{\prime}+\mathrm{Lek}_{\mathrm{c}} \mathrm{y}_{6}, \mathrm{y}_{7}(0)=-\frac{\mathrm{Nt}}{\mathrm{Nb}} \mathrm{y}_{5}(0)
\end{gathered}
$$

The above Eq. 21-27 are solved using Adam's-Moultan method of order 4 with an initial guess $r^{(0)}, s^{(0)}, t^{(0)}$. These guesses are updated by the Newton's method. The iterative process is repeated until, the following criteria is met:

$$
\max \left(\left|\mathrm{y}_{2}\left(\eta_{\infty}\right)\right|,\left|\mathrm{y}_{4}\left(\eta_{\infty}\right)\right|,\left|\mathrm{y}_{6}\left(\eta_{\infty}\right)\right|\right)<\epsilon
$$

where, $\epsilon>0$ is the tolerance. For all computation in this study we have fixed $\epsilon=10^{-5}$. The step sizes of $\Delta \eta=0.01$ and $\eta_{\max }=10$ were found to be satisfactory in obtaining sufficient accuracy.

\section{RESULTS AND DISCUSSION}

The objective of this study is to analyze the numerical results displayed in the shape of graphs and tables. The computations are carried out for various values of the magnetic parameter $\mathrm{M}$, velocity ratio parameter $\mathrm{A}$, radiation parameter $\mathrm{Nr}$, Eckert number $\mathrm{Ec}$, Lewis number $\mathrm{Le}$, Browian motion parameter $\mathrm{Nb}$, thermophoresis parameter $\mathrm{Nt}$ and Prandtl number $\mathrm{Pr}$ and the impact of these parameters on the velocity, temperature and concentration profiles is also discussed in detail.

Table 1 shows the comparison of calculated values with Ibrahim and Haq (2016), Ishak et al. (2006) and strong agreement with the values is found which showed high confidence of present simulation. In Table 1 by taking $\mathrm{M}=0$ and update the velocity ratio parameter $\mathrm{A}$, numerical results of the skin-friction coefficient $-\mathrm{f}^{\prime \prime}(0)$ are reproduced.

To further investigate the numerical technique used by ignoring the impacts of thermophoresis parameter $\mathrm{Nt}$ and Brownian motion parameter $\mathrm{Nb}$ and then compare the local Nusselt number $-\theta^{\prime}(0)$ by updating the Prandtl number as shown in Table 2. Excellent agreement of current results with those previously published results encourage us to use the present code.

Table 1: Comparison of the skin-friction coefficient - $\mathrm{f}$ " $(0)$ for different values of velocity ratio parameter $A$ and $M=0$

\begin{tabular}{lccr}
\hline A & Ibrahim and Haq (2016) Ishak et al. (2006) & Present results \\
\hline 0.1 & -0.9694 & -0.9694 & -0.9693874 \\
0.2 & -0.9181 & -0.9181 & -0.9181041 \\
0.3 & -0.8494 & -0.8494 & -0.8494202 \\
0.4 & -0.7653 & -0.7653 & -0.7653250 \\
0.5 & -0.6673 & -0.6673 & -0.6672632 \\
0.8 & -0.2994 & -0.2994 & -0.2993885 \\
1 & 0.0000 & 0.0000 & 0.0000000 \\
2 & 2.0175 & 2.0175 & 2.0175020 \\
3 & 4.7293 & 4.7293 & 4.7292940 \\
5 & 11.7520 & 11.7520 & 11.7519900 \\
7 & 20.4979 & 20.4979 & 20.4980600 \\
1 & 36.2574 & 36.2574 & 36.2575000 \\
\hline
\end{tabular}


Res. J. Applied Sci., 14 (6): 198-207, 2019

Table 2: Comparison of the local Nusselt number $-\theta^{\prime}(0)$ when $\mathrm{Nt}=0, \mathrm{Nb} \rightarrow 0$, for different values of $\operatorname{Pr}$ with formerly published data

\begin{tabular}{lcccc}
\hline Pr/A & Presentresults & Ibrahim andHaq (2016) & Mahapatra and Gupta (2002) & Hayat et al. (2012) \\
\hline $\mathbf{1}$ & & & & 0.603 \\
0.1 & 0.6008148 & 0.6028 & 0.625 & 0.602156 \\
0.2 & 0.6246567 & 0.6246 & 0.692 & 0.624467 \\
0.5 & 0.6926060 & 0.6924 & & 0.692460 \\
$\mathbf{1 . 5}$ & & & 0.777 & 0.776802 \\
0.1 & 0.7760525 & 0.7768 & 0.797 & 0.797122 \\
0.2 & 0.7969141 & 0.7971 & 0.863 & 0.864771 \\
0.5 & 0.8648634 & 0.8648 & & - \\
$\mathbf{2 . 0}$ & & & - & - \\
0.1 & 0.9256601 & 0.9257 & - & - \\
0.2 & 0.9447336 & 0.9447 & - & - \\
0.5 & 1.0114910 & 1.0116 & & - \\
\hline
\end{tabular}

Table 3: Comparison of the local Nusselt number $-\theta^{\prime}(0)$ for the different values of $\mathrm{Nt}$ and $\mathrm{Bi}$, if $\mathrm{Nb}=5, \mathrm{~A}=0: 3, \operatorname{Pr}=\mathrm{M}=1$, ie $=5$

\begin{tabular}{|c|c|c|c|c|c|c|c|c|c|}
\hline \multicolumn{2}{|l|}{$\mathrm{Bi}=0.1$} & \multicolumn{2}{|l|}{$\mathrm{Bi}=2$} & \multicolumn{2}{|l|}{$\mathrm{Bi}=5$} & \multicolumn{2}{|l|}{$\mathrm{Bi}=10$} & \multicolumn{2}{|l|}{$\mathrm{Bi}=100$} \\
\hline $\begin{array}{l}\text { Ibrahim and } \\
\text { Haq (2016) }\end{array}$ & $\begin{array}{l}\text { Present } \\
\text { results }\end{array}$ & $\begin{array}{l}\text { Ibrahim and } \\
\text { Haq (2016) }\end{array}$ & $\begin{array}{l}\text { Present } \\
\text { results }\end{array}$ & $\begin{array}{l}\text { Ibrahim and } \\
\text { Haq (2016) }\end{array}$ & $\begin{array}{l}\text { Present } \\
\text { results }\end{array}$ & $\begin{array}{l}\text { Ibrahim and } \\
\mathrm{Haq}(2016)\end{array}$ & $\begin{array}{l}\text { Present } \\
\text { results }\end{array}$ & $\begin{array}{r}\text { Ibrahim and } \\
\text { Haq (2016) }\end{array}$ & $\begin{array}{l}\text { Present } \\
\text { results }\end{array}$ \\
\hline 0.0861 & 0.0861460 & 0.4744 & 0.4743371 & 0.5531 & 0.5530363 & 0.5855 & 0.5854118 & 0.6180 & 0.6179690 \\
\hline 0.0861 & 0.0860621 & 0.4605 & 0.4604263 & 0.5313 & 0.5312279 & 0.5598 & 0.5596828 & 0.5880 & 0.5878806 \\
\hline 0.0859 & 0.0859333 & 0.4395 & 0.4394668 & 0.4993 & 0.4992715 & 0.5225 & 0.5224806 & 0.5415 & 0.5450010 \\
\hline 0.0857 & 0.0857102 & 0.4047 & 0.4046166 & 0.4486 & 0.4485220 & 0.4647 & 0.4646182 & 0.4798 & 0.4797399 \\
\hline 0.0855 & 0.0854758 & 0.3705 & 0.3704567 & 0.4017 & 0.4015988 & 0.4125 & 0.4124254 & 0.4224 & 0.4223108 \\
\hline 0.0852 & 0.0852291 & 0.3377 & 0.3376793 & 0.3591 & 0.3590596 & 0.3662 & 0.3661501 & 0.3725 & 0.3724754 \\
\hline 0.0834 & 0.0834207 & 0.1925 & 0.1924764 & 0.1940 & 0.1939228 & 0.1944 & 0.1943392 & 0.1948 & 0.1946867 \\
\hline
\end{tabular}

Furthermore, we reproduce the results by Ibrahim and Haq (2016) for the local Nusselt number $-\theta^{\prime}(0)$. Table 3 presents the local Nusselt number $-\theta^{\prime}(0)$ by taking random values of different physical parameters used such as Brownian motion, thermophoresis parameter, Biot number and the velocity ratio. It is observed in the table that the local Nusselt number $-\theta^{\prime}(0)$ is decreasing function of the thermophoresis parameter $\mathrm{Nt}$ and an increasing function of the Biot number Bi.

Impact of velocity ratio parameter on the velocity: Figure 1 designates that by enlarging $A(A>1)$, the width of the hydrodynamic boundary layer increases and it declines by decreasing $\mathrm{A}(\mathrm{A}<1)$. Physically, the ratio between free stream velocity and the stretching velocity is $>1$, if stretching velocity becomes less than the free stream velocity. Consequently, flow velocity is increased whereas retarding force is declined.

Impact of magnetic parameter on the velocity: Figure 2 divulges the impact of magnetic parameter on the velocity $f^{\prime}(0)$. Here, due to magnetic field an opposing force which is called Lorentz force, appears which resist the flow of fluid and consequently the flow of velocity declines.

Impact of Prandtl number on the temperature: Figure 3 designates the impact of $\mathrm{Pr}$ on the temperature

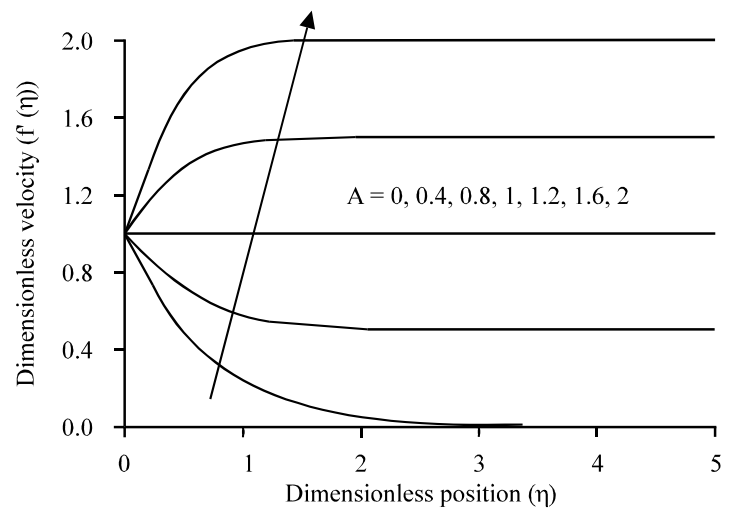

Fig. 2: Velocity profile $f^{\prime}(0)$ for different values of velocity ratio $\mathrm{A}$ when $\mathrm{Pr}=1.0, \mathrm{Nr}=3, \mathrm{Ec}=$ $1.0, \mathrm{k}_{\mathrm{c}}=1.0, \mathrm{Nt}=0.5, \mathrm{Nb}=0.5, \mathrm{Le}=\mathrm{Bi}=5.0$, $\mathrm{M}=1.0$

profile $\theta(\eta)$. It is clear from figure that the temperature of the flow field is the decreasing function of Pr. It is because of the way when Pr of fluid is high then thermal diffusion is low if it is compared with the viscous diffusion. Consequently, the coefficient of heat transfer declines as well as shrinks the thickness of the boundary layer.

Impact of thermophoresis parameter on the temperature: Figure 4 delineates the influence of $\mathrm{Nt}$ on the temperature profile. When the effects of 
Res. J. Applied Sci., 14 (6): 198-207, 2019

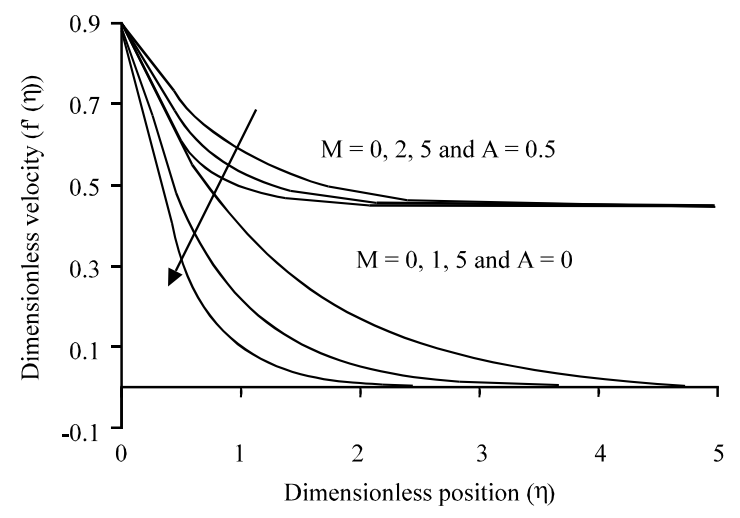

Fig. 3: Velocity profile $\mathrm{f}^{\prime}(0)$ for different values of $\mathrm{M}$ when $\operatorname{Pr}=1.0, \mathrm{Nr}=3, \mathrm{Ec}=1.0, \mathrm{k}_{\mathrm{c}}=1.0, \mathrm{Nt}=0.5$, $\mathrm{Nb}=0=5, \mathrm{Le}=\mathrm{Bi}=5.0$

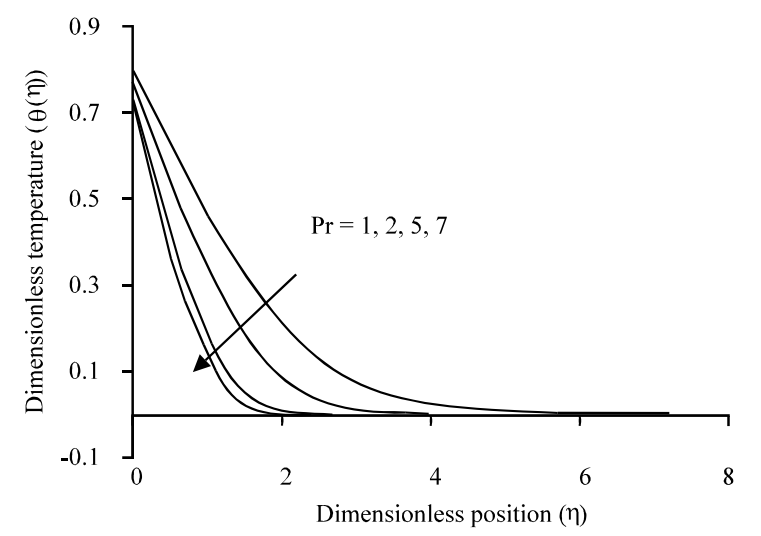

Fig. 4: Variation of $\theta(\eta)$ for variation values of $\operatorname{Pr}$ when $\mathrm{M}=1.0, \mathrm{~A}=\mathrm{Nt}=\mathrm{Nb}=0.5, \mathrm{Bi}=\mathrm{Le}=5.0$ and $\mathrm{Ec}=\mathrm{Nr}=0, \mathrm{k}_{\mathrm{c}}=1.0$

thermophoretic increase, the relocation of the nanoparticles relocate from hot part of the surface to the cold ambient fluid and consequently at the boundary, temperature is increased. This sequels in the thickening of thermal boundary layer.

Impact of convective heating on the temperature: Figure 5 describes the effect of the convective heating which is also known as the Biot number on the temperature profile $\theta(\eta)$. Numerically, it can be calculated by dividing the convection on the surface to the conduction into surface of an object. When $\mathrm{Bi}$ increases, it causes increase in the temperature on surface which sequels in the thickening of the thermal boundary layer.

Impact of velocity ratio parameter on the temperature: The effect of velocity ratio parameter $A$ on the temperature profile $\theta(\eta)$ has been highlighted by Fig. 6. As we increase the value of velocity ratio

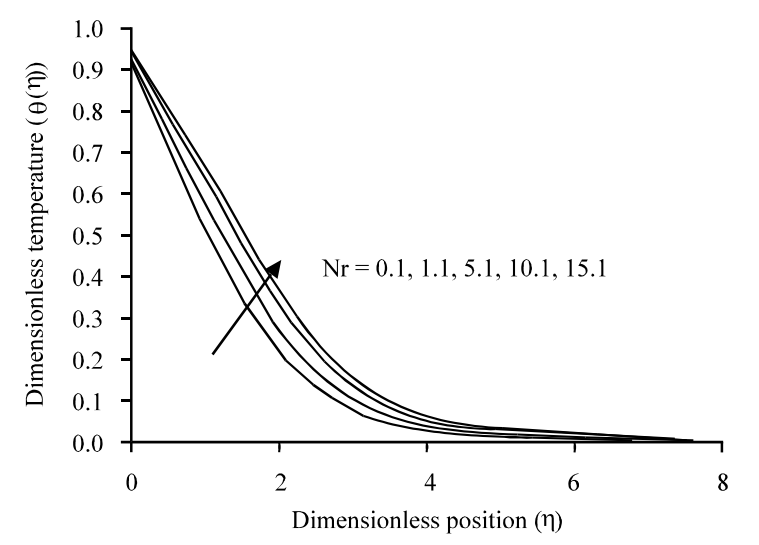

Fig. 5: Variation of $\theta(\eta)$ for variation values of $\mathrm{Nt}$ when $\operatorname{Pr}=\mathrm{M}=1.0, \mathrm{~A}=\mathrm{Nb}=0.5, \mathrm{Bi}=\mathrm{Le}=$ $5.0, \mathrm{Ec}=\mathrm{Nr}=0.5$ and $\mathrm{k}_{\mathrm{c}}=1.0$

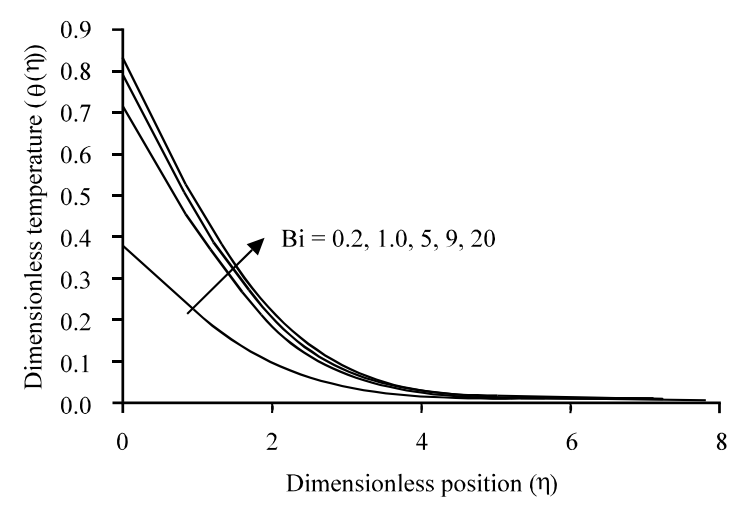

Fig. 6: Variation of $\theta(\eta)$ for variation values of $\mathrm{Bi}$ when $\operatorname{Pr}=\mathrm{M}=1.0, \mathrm{~A}=\mathrm{Nt}=\mathrm{Nb}=0.5, \mathrm{Le}$ $=5.0, \mathrm{Ec}=\mathrm{Nr}=0.5$ and $\mathrm{k}_{\mathrm{c}}=1.0$

parameter $\mathrm{A}$, the temperature at the surface declines and furthermore, it also declines the thickness of the thermal boundary layer.

Impact of radiation parameter on the temperature: The influence of radiation parameter on profile of temperature distribution is displayed in Fig. 7. Temperature increases with the increase of thermal radiation parameter $\mathrm{Nr}$. The effect of radiation is intensify the heat transfer, thus, radiation should be at its minimum in order to fascilate cooling process.

Impact of viscous dissipation on the temperature: Figure 8 show the impact of the viscous dissipation on the temperature profile. When the value of the viscous dissipation is increased, the fluid region is allowed to store the energy. As a result of dissipation due to fractional heating, heat is generated. From this figure, we examine that the value of the thermal boundary thickness increases and it will eventually increase the temperature. 


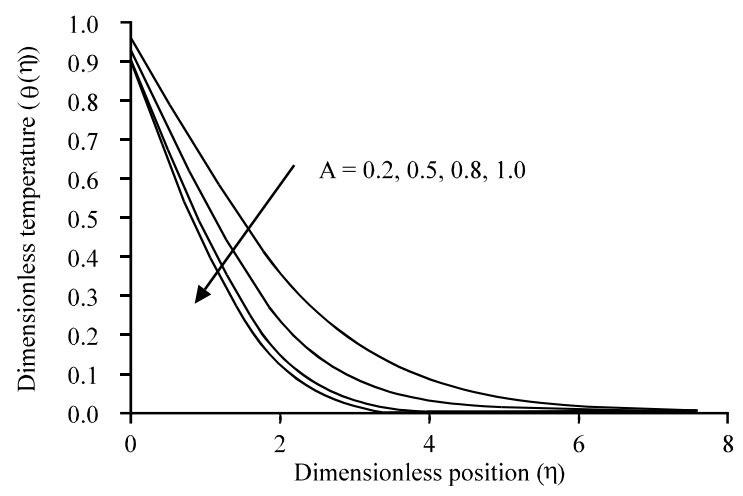

Fig. 7: Variation of $\theta(\eta)$ for variation values of $A$ when $\operatorname{Pr}=\mathrm{M}=1.0, \mathrm{Nt}=\mathrm{Nb}=0.5, \mathrm{Bi}=$ $\mathrm{Le}=5.0, \mathrm{Ec}=\mathrm{Nr}=0.5$ and $\mathrm{k}_{\mathrm{c}}=1.0$

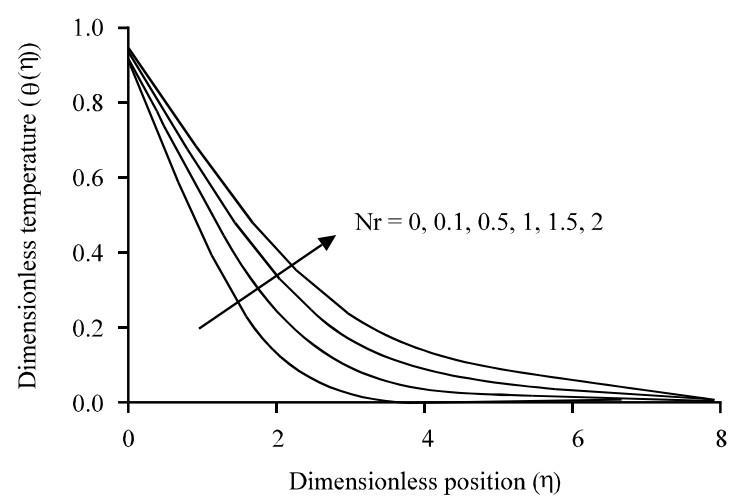

Fig. 8: Variation of $\theta(\eta)$ for variation values of $\mathrm{Nr}$ when $\operatorname{Pr}=\mathrm{M}=1.0, \mathrm{Nt}=\mathrm{Nb}=\mathrm{A}=0.5, \mathrm{Bi}=\mathrm{Le}=$ $5.0, \mathrm{Ec}=0.5$ and $\mathrm{k}_{\mathrm{c}}=1.0$

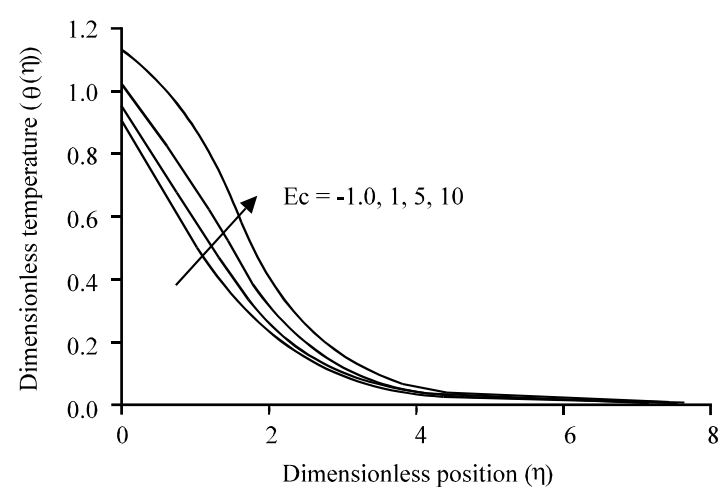

Fig. 9: Variation of $\theta(\eta)$ for variation values of $E c$ when $\operatorname{Pr}=\mathrm{M}=1.0, \mathrm{Nt}=\mathrm{Nb}=\mathrm{A}=0.5, \mathrm{Bi}=\mathrm{Le}=$ $5.0, \mathrm{Nr}=0.5$ and $\mathrm{k}_{\mathrm{c}}=1.0$

Impact of Prandtl number on the concentration: The effect of the variation in the Pr on the concentration profile is observed in Fig. 9. It is noticed from the figure

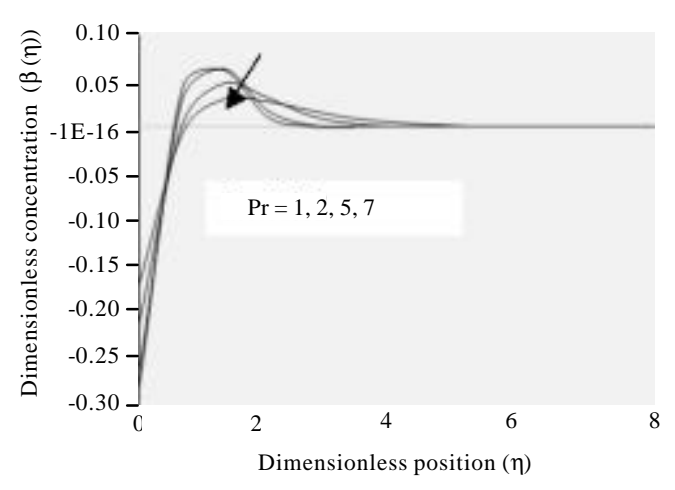

Fig. 10: Variation of $\beta(\eta)$ for variation values of $\operatorname{Pr}$ when $\mathrm{M}=1.0, \mathrm{~A}=\mathrm{Nt}=\mathrm{Nb}=0.5, \mathrm{Bi}=\mathrm{Le}=$ $5.0, \mathrm{Ec}=\mathrm{Nr}=0.5$ and $\mathrm{k}_{\mathrm{c}}=1.0$

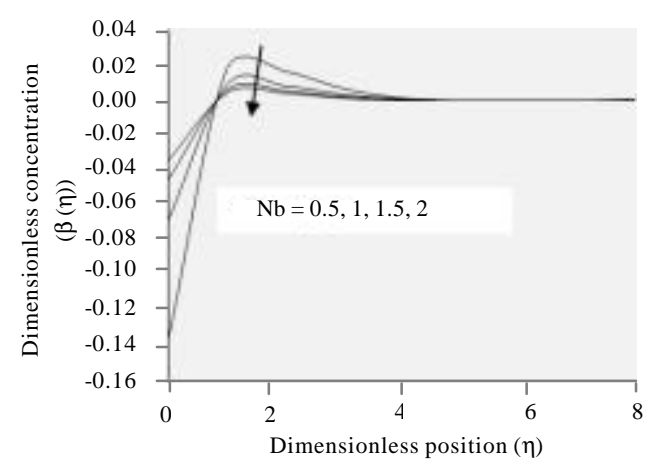

Fig. 11: Variation of $\beta(\eta)$ for variation values of $\mathrm{Nb}$ when $\operatorname{Pr}=\mathrm{M}=1.0, \mathrm{Nt}=\mathrm{A}=0.5, \mathrm{Bi}=$ $\mathrm{Le}=5.0, \mathrm{Ec}=\mathrm{Nr}=0.5$ and $\mathrm{k}_{\mathrm{c}}=1.0$

as the value of Prandtl number rises, the nanoparticles scattered out toward the outward, consequently, the nanoparticles concentration at the surface decreases.

Impact of Brownian motion parameter on the concentration: The impact of the Brownian motion parameter $\mathrm{Nb}$ on the concentration $\beta(\eta)$ is illustrated by Fig. 10. When we increase the effect of $\mathrm{Nb}$, the concentration profile $\beta(\eta)$ also increases initially but it starts decreasing far away from the wall.

Impact of thermophoresis parameter on the concentration: It seems clearly from the Fig. 11 that if we increase the thermophoretic force it causes decline in the concentration profile $\beta(\eta)$ at the surface which is reverse in nature to the case of the $\mathrm{Nt}$.

Impact of Lewis number on the concentration: The concentration vs. Lewis number has been illustrated by Fig. 12. Increasing Le corresponding to the concentration. 


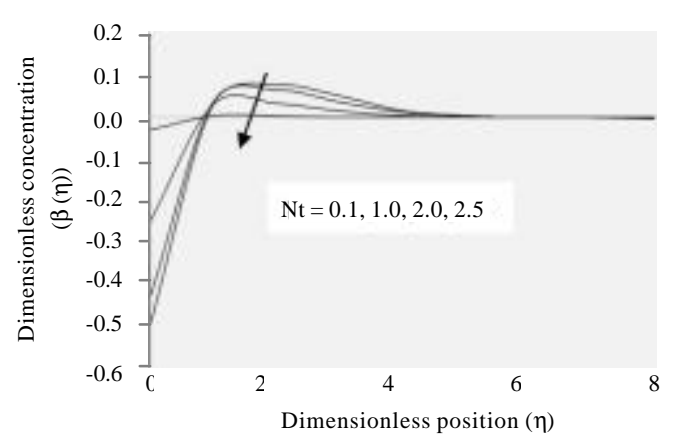

Fig. 12: Variation of $\beta(\eta)$ for variation values of $\mathrm{Nt}$ when $\operatorname{Pr}=\mathrm{M}=1.0, \mathrm{~A}=\mathrm{Nb}=0.5, \mathrm{Bi}=$ $\mathrm{Le}=5.0, \mathrm{Ec}=\mathrm{Nr}=0.5$ and $\mathrm{k}_{\mathrm{c}}=1.0$

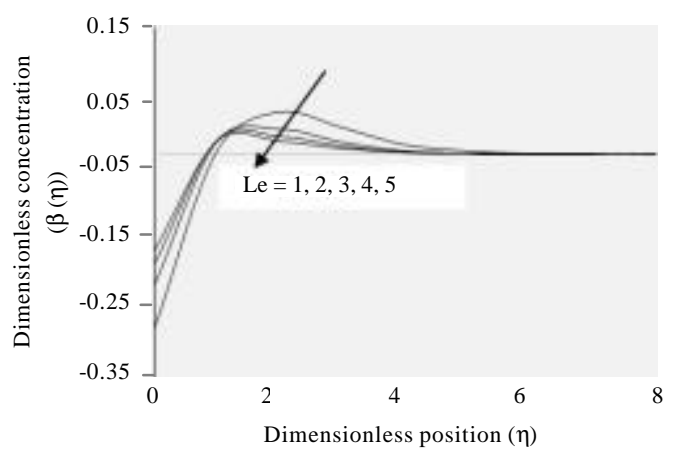

Fig. 13: Variation of $\beta(\eta)$ for variation values of Le when $\mathrm{Pr}=\mathrm{M}=1.0, \mathrm{Nt}=\mathrm{Nb}=\mathrm{A}=0.5, \mathrm{Bi}=\mathrm{Le}$ $=5.0, \mathrm{Ec}=\mathrm{Nr}=0.5$ and $\mathrm{k}_{\mathrm{c}}=1.0$

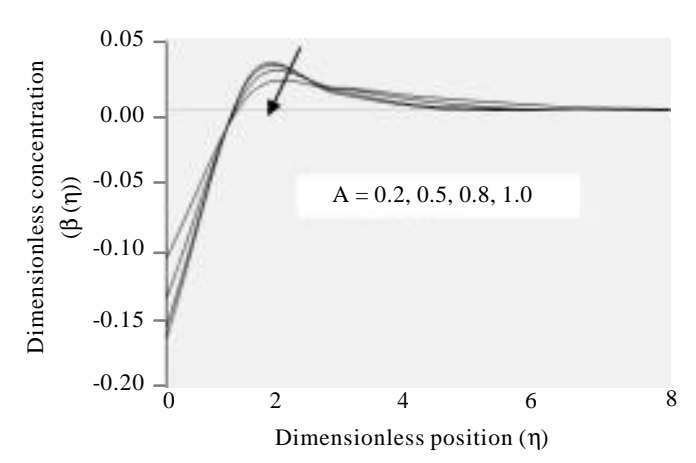

Fig. 14: Variation of $\beta(\eta)$ for variation values of $A$ when $\operatorname{Pr}=\mathrm{M}=1.0, \mathrm{Nt}=\mathrm{Nb}=0.5, \mathrm{Bi}=\mathrm{Le}=5.0, \mathrm{Ec}=$ $\mathrm{Nr}=0.5$ and $\mathrm{k}_{\mathrm{c}}=1.0$

As a result, initially, the concentration on surface increases but after a while a bit away from the surface it starts decreasing.

Impact of velocity ratio parameter on the concentration: Figure 13 and 14 demonstrates the

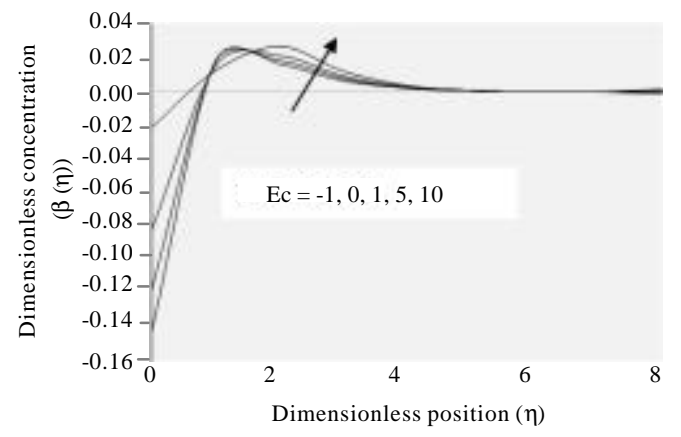

Fig. 15: Variation of $\beta(\eta)$ for variation values of $E c$ when $\mathrm{Pr}=\mathrm{M}=1.0, \mathrm{Nt}=\mathrm{Nb}=\mathrm{A}=0.5, \mathrm{Bi}=\mathrm{Le}$ $=5.0, \mathrm{Nr}=0.5$ and $\mathrm{k}_{\mathrm{c}}=1.0$

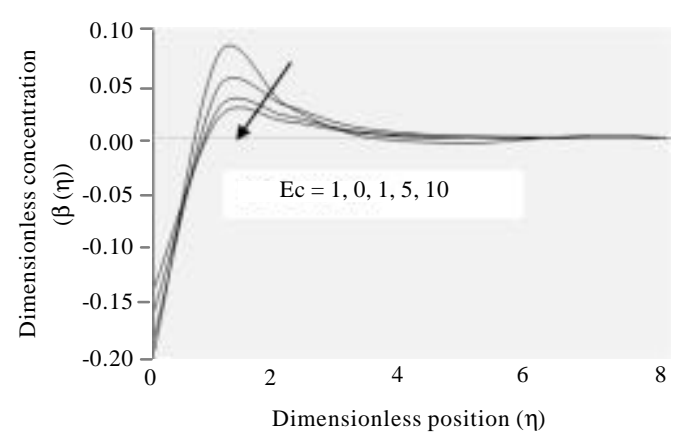

Fig. 16: Variation of $\beta(\eta)$ for variation values of $k_{c}$ when $\operatorname{Pr}=\mathrm{M}=1.0, \mathrm{Nt}=\mathrm{Nb}=\mathrm{A}=0.5, \mathrm{Bi}=\mathrm{Le}$ $=5.0, \mathrm{Nr}=0.5$ and $\mathrm{k}_{\mathrm{c}}=1.0$

concentration vs. velocity ratio. It has the similar effects on the concentration profile as the effect of Lewis number is noted on concentration. As the concentration distribution decreases by increasing the velocity ratio parameter A.

Impact of viscous dissipation on the concentration: Figure. 15 display the influence of Eckert number Ec on concentration profile. It is observed that the concentration of the fluid decreases near the plate. However, it rises away from the surface as the value of Eckert number is enhanced.

Impact of chemical reaction parameter on the concentration: Figure 16 explains the influence of the chemical reaction parameter on the profile of concentration. It is noted that increasing values of chemical reaction parameter concentration as well as the thickness of concentration decrease. It is because of the fact that the chemical reaction in this system results in chemical dissipation and therefore, results in decrease in the profile of concentration. The most significant 
influence is that chemical reaction tends to increase the overshoot in the concentration profiles and their associated boundary layer.

\section{CONCLUSION}

After a thorough investigation, we have reached the following concluding observation. The velocity profile increases by increasing a but the temperature and concentration profiles decrease by increasing $\mathrm{A}$. The magnetic parameter $\mathrm{M}$ has the same increasing influence on the temperature and the concentration field but opposite on the velocity field. The temperature field $\theta(\eta)$ and the concentration field $\beta(\eta)$ reduce with an increase in the Prandtl number.

Temperature field $\theta(\eta)$ increases with an increase in thermal radiation $\mathrm{Nr}$. For larger values of Lewis number $\mathrm{Le}$, thermophoresis parameter Nt and Brownian motion parameter $\mathrm{Nb}$ has an increasing effect on the concentration field $\beta(\eta)$

Increase in viscous dissipation increases temperature and concentration profile. By increasing values of chemical reaction parameter concentration as well as the thickness of concentration decrease.

\section{ACKNOWLEDGEMENT}

The researchers would like to thanks to Prof. Koneru S.R., Retired Professor, Department of Mathematics, IIT Bombay for his support throughout this research work.

\section{NOMENCLATURE}

$\begin{array}{ll}\mathrm{B} & : \text { Magnetic field strength }\left(\mathrm{Wbm}^{-2}\right) \\ \mathrm{a} & : \text { Constant }\left(\mathrm{s}^{-1}\right) \\ \mathrm{D}_{\mathrm{B}} & : \text { Brownian Diffusion coefficient } \\ \mathrm{D}_{\mathrm{T}}: \text { Thermophoretic Diffusion coefficient } \\ \mathrm{K} & : \text { Thermal conductivity }\left(\mathrm{Wm}^{-1} \mathrm{k}^{-1}\right) \\ \sigma^{*} & : \text { Stefan-Boltzmann constant }\left(\mathrm{kg}^{-1} \mathrm{~K}^{-4}\right) \\ \mathrm{k}^{*}: \text { Mean absorption } \\ \mathrm{Ec}: \text { Eckert number } \\ \mathrm{Le}: \text { Lewis number } \\ \mathrm{M}: \text { Magnetic parameter } \\ \mathrm{Nb}: \text { Brownian motion parameter } \\ \mathrm{Nt}: \text { Thermophoresis parameter } \\ \mathrm{Nu}: \text { Nusselt number } \\ \mathrm{Nur}: \text { Reduced Nusselt number } \\ \mathrm{Pr}: \text { Prandtl number } \\ \mathrm{p} \quad: \text { Pressure } \\ \mathrm{c}_{\mathrm{f}}: \text { Heat capacity of the fluid }\left(\mathrm{Jm}^{-3} \mathrm{~K}^{-1}\right) \\ \mathrm{c}_{\mathrm{p}}: \text { Effective heat capacity of the nanoparticle material } \\ \mathrm{q}_{\mathrm{r}} \quad: \text { Radiative heat flux }\left(\mathrm{km}^{-2}\right)\end{array}$

$\mathrm{q}_{\mathrm{m}}:$ Wall mass flux

$\mathrm{q}_{\mathrm{w}}$ : Wall heat flux

$\operatorname{Re}_{\mathrm{x}}$ : Local Reynolds number

Shr : Reduced Sherwood number

$\mathrm{Sh}_{\mathrm{x}}$ : Local Sherwood number

$\mathrm{T}$ : Fluid temperature (K)

$\mathrm{T}_{\mathrm{w}}:$ Temperature at the stretching sheet $(\mathrm{K})$

$\mathrm{T}_{\infty}$ : Ambient temperature $(\mathrm{K})$

$\mathrm{u}, v$ : Velocity components along $\mathrm{x}$ and $\mathrm{y}$ axis $\left(\mathrm{msec}^{-1}\right)$

$\mathrm{u}_{\mathrm{w}}:$ : Velocity of the stretching sheet $\left(\mathrm{msec}^{-1}\right)$

$\mathrm{x}, \mathrm{y}$ : Cartesian coordinates ( $\mathrm{x}$ axis is aligned along the stretching surface and y axis is normal to it) (L)

$\alpha \quad$ : Thermal diffusivity $\left(\mathrm{m}^{2} \mathrm{sec}^{-1}\right)$

$\beta$ : Dimensionless nanoparticle volume fraction

$\eta \quad$ : Similarity variable

$\psi \quad$ : Stream function $\left(\mathrm{m}^{2} \mathrm{sec}^{-1}\right)$

$\theta \quad$ : Dimensionless temperature

$\rho_{\mathrm{f}} \quad$ : Fluid density $\left(\mathrm{kg}^{-3}\right)$

$\rho_{\mathrm{p}}:$ Nanoparticle mass density $\left(\mathrm{kg}^{-3}\right)$

$\sigma$ : Electrical conductivity of the fluid

$\tau$ : Parameter defined by ratio between the effective heat capacity of the nanoparticle material and heat capacity of the fluid $\tau=(\rho c)_{\mathrm{p}} /(\rho c)_{\mathrm{f}}$

\section{REFERENCES}

Afify, A.A., 2004. MHD free convective flow and mass transfer over a stretching sheet with chemical reaction. Heat Mass Transfer., 40: 495-500.

Beg, O.A., M.S. Khan, I. Karim, M.M. Alam and M. Ferdows, 2014. Explicit numerical study of unsteady hydromagnetic mixed convective nanofluid flow from an exponentially stretching sheet in porous media. Applied Nanosci., 4: 943-957.

Buongiorno, J., 2006. Convective transport in nanofluids. ASME J. Heat Transfer, 128: 240-250.

Choi, S.U.S., 1995. Enhancing Thermal Conductivity of Fluids with Nanoparticles. In: Developments and Applications of Non-Newtonian Flows, Siginer, D.A. and H.P. Wang (Eds.). American Society of Mechanical Engineers, New York, pp: 99-105.

Cortell, R., 2012. Heat transfer in a fluid through a porous medium over a permeable stretching surface with thermal radiation and variable thermal conductivity. Can. J. Chem. Eng., 90: 1347-1355.

Hayat, T., M. Mustafa, S.A. Shehzad and S. Obaidat, 2012. Melting heat transfer in the stagnation-point flow of an Upper-Convected Maxwell (UCM) fluid past a stretching sheet. Intl. J. Numer. Methods Fluids, 68: 233-243.

Ibrahim, W. and R.U. Haq, 2016. Magnetohydrodynamic (MHD) stagnation point flow of nanofluid past a stretching sheet with convective boundary condition. J. Braz. Soc. Mech. Sci. Eng., 38: 1155-1164. 
Ishak, A., R. Nazar and I. Pop, 2006. Mixed convection boundary layers in the stagnation-point flow toward a stretching vertical sheet. Meccanica, 41: 509-518.

Khan, W.A. and I. Pop, 2011. Flow and heat transfer over a continuously moving flat plate in a porous medium. J. Heat Transfer, 133: 1-5.

Kuznetsov, A.V. and D.A. Nield, 2010. Natural convective boundary-layer flow of a nanofluid past a vertical plate. Int. J. Thermal Sci., 49: 243-247.

Mahapatra, T.R. and A.S. Gupta, 2002. Heat transfer in stagnation-point flow towards a stretching sheet. Heat Mass Transfer, 38: 517-521.
Makinde, O.D., W.A. Khan and Z.H. Khan, 2013. Buoyancy effects on MHD stagnation point flow and heat transfer of a nanofluid past a convectively heated stretching/shrinking sheet. Intl. J. Heat Mass Transfer, 62: 526-533.

Nadeem, S. and R.U. Haq, 2014. Effect of thermal radiation for megnetohydrodynamic boundary layer flow of a nanofluid past a stretching sheet with convective boundary conditions. J. Comput. Theoret. Nanosci., 11: 32-40.

Naramgari, S. and C. Sulochana, 2016. Dual solutions of radiative MHD nanofluid flow over an exponentially stretching sheet with heat generation/absorption. Appl. Nanosci., 6: 131-139. 